\title{
A revision of the Helvella acetabulum group (Pezizales) in Fennoscandia
}

\author{
HARRI HARMAJA
}

\begin{abstract}
HARMAJA, H. 1977: A revision of the Helvella acetabulum group (Pezizales) in Fennoscandia. - Karstenia 17: 45-58.

What has been regarded as Helvella acetabulum (St-Am.) Quél. in Fennoscandia is shown to be a diverse assemblage of species. This is due partly to a collective species concept, partly to true misidentifications. Two new species are described: Helvella arctoalpina Harmaja and $H$. dryadophila Harmaja. The diagnostic characters, phenology and distribution of $H$. acetabulum s.str. and the two new species are presented; the concept of the first taxon is restricted to a large, rather pale, early southern species, while the other two are small, dark, late arctic-alpine species. Differences in anatomy, including some 'new' features, were observed between the species, and the usefulness of such characters at specific level in the genus Helvella St-Am. is emphasized.

Four quantitative characters of $H$. acetabulum, $H$. arctoalpina and $H$. dryadophi$l a$ were analysed statistically. The material for $H$. dryadophila was insufficient for comparison, but highly to fairly significant differences could be shown between the two other species.

$H$. pocillum Harmaja, described earlier, is reported as new to Norway, this being the second known collection of the species. $H$. palustris Peck, which does not belong to the acetabulum group, is a valid species occurring in northern Finland and new to this country.
\end{abstract}

Harri Harmaja, Botanical Museum, University of Helsinki, Unioninkatu 44, SF-00170 Helsinki 17, Finland

\section{Introduction}

The genus Helvella St-Am. (Pezizales) was recently monographed by the Danish mycologist Dr. Henry Dissing (1966), who made a most valuable contribution to the clarification of old epithets and the examination of a great many type and other collections from different parts of the world. Unfortunately, however, this study contains certain discrepancies between the key, the species descriptions, the lists of specimens examined (especially their published label notes), and the distribution maps. There are also errors in printing, spelling of names, and nomenclatoral matters, and, for some reason, the Finnish Helvella material was not included (except for a very few specimens). The species concept is too collective in the work. Careful comparison of the macroscopic and anatomical characters, and the distribution and phenology of different collections would have revealed more specific hiatuses in the material of the monograph. As regards the microscopic characters, exact illustrations are given of the individual excipular cells, but the descriptions and illustrations of the anatomy of the excipulum are somewhat too simplified and generalized.

Dissing's descriptions are undoubtedly more accurate than any published earlier, but my own studies have revealed more specific differences in the excipular details, including some features which have not been used previously in the taxonomy of Helvella or the Pezizales in general (cf. also Harmaja 1977). The monograph also contains obvious misidentifications, which often appear to be due to failure to examine the specimens microscopically. The type specimen of $H$. pocillum Harmaja (Harmaja 1976) was determined and published by Dissing as $H$. acetabulum (St-Am.) Quél., a species which, according to Dissing himself, has spores 16$19 \mu \mathrm{m}$ long, whereas the spores of the specimen are surprisingly large for a Helvella, measuring 25-28 
$\mu \mathrm{m}$. The material also contained mixed collections. E.g. a specimen named and published as $H$. acetabulum (Norway, Oppland, Lom, Høyrokampen, Dryas association, 29.VIII.1957 Eckblad, O), consisting of 83 apothecia, did not contain $H$. acetabulum s.str., but no less than four other species of Helvella instead: $H$. arctoalpina $\mathrm{n}$. sp. (31 apoth.), $H$. dryadophila $\mathrm{n}$. sp. (10 apoth.), H. pocillum $\mathrm{n}$. sp. (40 apoth.; already described on the basis of another specimen in Harmaja 1976), and $H$. solitaria Karst. (2 apoth.; syn. H. queletii Bres.: see Harmaja 1977).

The fact that $H$. acetabulum appeared to have too wide a phenological amplitude in the monograph made me begin some revisory work in the genus Helvella. Some taxonomically apparently uniform species of this genus do in fact seem to possess long fruiting periods (and wide distributions), but certain things made me suppose that $H$. acetabulum is properly a spring to early summer species in Europe. According to the label notes of the specimens given in Dissing (1966), the fruiting period in Sweden and Norway lasts from mid-May to late September (there is, however, some discordance between this information and the fruiting period he gives at the end of the species description). I have examined 13 of the 15 collections (partly mixed ones; see e.g. above) reported by him from these two countries as collected after July 22 and found that they represent six different Helvella species, but not $H$. acetabulum s. str., and one species of Otidea (Pers.) Bon.: $H$. arctoalpina $\mathrm{n} . \mathrm{sp} .(9$ exx.), $H$. dryadophila n. $\mathrm{sp}$. (2), $H$. pocillum n. sp. (2), H. solitaria (2 in mixed collections; one was mentioned above, the other: Norway, Oppland, Lom, Blåh $\varnothing$, 30.VIII.1957 Eckblad, O), H. costifera Nannf. coll. (1; Norway, Buskerud, Hol, Dryas association, 4.IX.1960 Sivertsen, O), H. sp. (1; Sweden, Uppland, Danderyd, 12.IX.1948 Berggren, S; a species with large spores, $18-24 \times 11.5-14 \mu \mathrm{m}$, unknown to $\mathrm{me}$ ), and Otidea propinquata (Karst.) Harmaja (syn. O. indivisa Vel.; O. abietiná auct.) (1; Sweden, Södermanland, Halla, 23.IX.1962 Julin, UPS).

Kallio \& Kankainen (1964) reported a late find of $H$. acetabulum from Utsjoki, Inari Lapland, Finland (17.VIII.1964 Kallio, TUR). My examination showed that it does not belong to $H$. acetabulum either; it represents the variable species $H$. costifera.

If the three fruiting diagrams in Fig. 14 were united into one histogram, the graph would possess a long 'tail' on the right. Such asymmetry and deviation from normal distribution (which would be even more pronounced if the data of all the specimens published under $H$. acetabulum in Dissing 1966 were included) would indeed have suggested that the material is heterogeneous and in need of revision.

Besides the phenological features, the distribution of $H$. acetabulum sensu Dissing attracted by attention. A more or less clear division into southern and northern or alpine subareas in a species distribution should always suggest that the material concerned may require revision (though species do exist, in Helvella also, which occur over wide regions from beech woods to alpine and arctic areas).

It can be added that a specimen deposited in $\mathrm{S}$ under $H$. acetabulum, which for some reason was not included in Dissing's monograph and lacks any annotation of his, proved to belong to $H$. silvicola (Beck) Harmaja (Otidea auricula auct., Wynnella silvicola (Beck) Nannf.). The label notes may be summarized as follows: 'Acetabula sulcata (Pers.) Fuck., (Sweden,) Uppland, Lovö, Prästvik, 6.V. 1945 Santesson, det. F. Petrak 1951'. On the other hand, one of the specimens published as $H$. costifera in Dissing (1966) proved to belong to $H$. acetabulum s. str.: Sweden, Västmanland, Sala, Gröna gången, Måns-Ols, 2.VII.1945 Morander 60, UPS.

Thus, the Fennoscandian material determined previously as $H$. acetabulum comprises (1) true $H$. acetabulum, (2) three new species: $H$. arctoalpina, $H$. dryadophila and $H$. pocillum, and (3) some obvious misidentifications. The two first new species will be described here, and $H$. pocillum has already been published (Harmaja 1976). H. pocillum was earlier known only from the type collection from Swedish Lapland. It is not treated in detail in the present paper but some notes on it are given. A mixed collection, mentioned above, contained the second known specimen of $H$. pocillum, which was also the first from Norway. Its dry apothecia are shown in Fig. 6, and the stars in Fig. 15 indicate its known distribution.

Some other revisions of Helvella will be done by me later and one of them is published together with the present contribution (Harmaja 1977). I wish to report already here that, after examining the type specimen macroscopically and microscopically, I consider $H$. palustris Peck a valid species. This agrees with the opinion of Weber (1972), but Dissing (1966) treated the species as synonymous with $H$. lacunosa $\mathrm{Fr}$. H. palustris has been found in some localities on moist calcareous ground in northern Finland, and is new to this country. 


\section{Materials and methods}

The dried Fennoscandian material deposited as $H$. acetabulum has been examined in most of the important Fennoscandian herbaria (H, HFR, O, S, TUR, UPS), and the 20 specimens listed below have been investigated in detail. Some other material has also been studied. $H$. acetabulum s. str. was examined when fresh as well. The list below comprises all the specimens, nine and two respectively, of the two new species $H$. arctoalpina and $H$. dryadophila, and nine specimens of $H$. acetabulum s. str. examined for comparison. The material of $H$. acetabulum was chosen deliberately from different geographic areas (even outside Fennoscandia) within its distribution, and it includes the northernmost specimens of Fennoscandia; Fennoscandian specimens collected late in the fruiting period have also been included. These 20 specimens were all examined macroscopically and under the microscope, free-hand sections being taken from the apothecium ca. $2-4 \mathrm{~mm}$ below the cup margin and mounted in Melzer's reagent. Some sections of each species were also mounted in $5 \% \mathrm{KOH}$ and heated cotton blue.

Statistical analyses were made of the variation in spore length, spore width, paraphysis apex diameter and the diameter of the excipular end cells in each of the three species, as represented by the 20 specimens. Twenty measurements (cf. p. 54) were made per specimen for each of these four characters, on sections of one mature dried apothecium mounted in Melzer's reagent. The measurements, made with an ocular micrometer at a magnification of $\times 600$, are exact to $0.5 \mu \mathrm{m}$. The arithmetical mean, standard deviation, and standard error were calculated for the variation of each of the four characters, for each specimen and, from the specimen means, for the whole material of each of the three species. The confidence limits at the $95 \%$ level were also calculated for all the 80 means of the specimens and the eight specific means of $H$. acetabulum and $H$. arctoalpina (confidence limits for specific means were not calculated for the limited material of $H$. dryadophila).

Student's test (t test) was used to examine whether the four characters, as represented by the nine mean values of the specimens, differ significantly between $H$. acetabulum and $H$. arctoalpina, the two species with sufficient material. All the statistical calculations were made with a Hewlett-Packard 9100B calculator, using the appropriate programmes.

The data presented in Table 1 are based on all the material seen. Besides the nine specimens examined in detail, several other collections of $H$. acetabulum s. str., including all the northern and late ones, were studied microscopically. Free-hand sections of dried apothecia were mounted in Melzer's reagent and studied at a magnification of $\times 600$, but the matter in which the paraphysis tips are embedded was observed in heated cotton blue, and the wall thicknesses of the textura prismatica cells were measured at a magnification of $\times 1500$. The zonal distributions of the species are described in the terms of Ahti et al. (1968).
Specimens examined in detail

\section{H. acetabulum}

1. Finland, Varsinais-Suomi, Lohja rural district, Virkkala, 30.V.1967 Harmaja (H).

2. Finland, Uusimaa, Sipoo, Östersundom, 6.VI.1937 Häyrén (H).

3. Sweden, Västmanland, Sala, the town, 22.VII.1956 Morander (UPS).

4. Sweden, Jämtland, Östersund, Odensala, 22.VII.1950 Holm (UPS).

5. Norway, Akershus, Baerum, Kalvøya, 21.VI.1953 Eckblad $(\mathrm{O})$.

6. Norway, Nordland, Vega, Vega, 3.VII.1962 Vasshaug (O).

7. Denmark, Sjaelland, Boserup, 6.VI.1950 M. Lange, Bille-Hansen \& Eckblad (O).

8. Austria, Niederösterreich, Velm, coll. in May, G. de Beck (Krypt. exs. (Vindob.) no. 139, H).

9. Canada, Ontario, L. Opinicon, Queen's Biol. Sta., 9.VI.1963 Kendrick (H).

\section{H. arctoalpina}

1. Sweden, Jämtland, Åre, Storlien, fjeld Rekdalshöjden, top of the fjeld, on bare soil among fjeld plants, VIII. 1943 Romell (UPS).

2. Sweden, Torne Lappmark, Jukkasjärvi, fjeld Låktatjåkko, on talus on slopes above Kopparåsen railway station, 5.VIII.1943 Sandberg (UPS).

3. Norway, Oppland, Lom, eastern end of lake Bøvertunvatn, alt. ca. $950 \mathrm{~m}, 22$.VII.1967 L $\emptyset k$ ken (O).

4. Norway, Oppland, Lom, Bøverdalen, fjeld Høyrokampen, alt. 1250-1300 m, 10.VIII.1952 Nordhagen (O).

5. Norway, Oppland, Lom, fjeld Høyrokampen, alt. 1400-1440 m, Dryas octopetala assoc., 29. VIII.1957 Eckblad, p.p. (O).

6. Norway, Oppland, Lom, western part of fjeld Blåhø, Dryas heath, 30.VIII.1957 Eckblad, p.p. (O).

7. Norway, Hordaland, Eidfjord, fjeld Dyranut, Dryas heath, 1.VIII.1959 Eckblad (type; O).

8. Norway, Hordaland, Eidfjord, fjeld Dyranut, Dryas assoc., 12.VIII.1960 Eckblad (O).

9. Norway, Finnmark, Nordkapp, Magerøya, fjeld Duksfjordfjell, together with Braya purpurascens, 30.VII.1965 Ryvarden (O).

\section{H. dryadophila}

1. Sweden, Torne Lappmark, Jukkasjärvi, fjeld Nuolja, on very top of the fjeid, 7.VIII.1903 Vestergren (S).

2. Norway, Oppland, Lom, tjeld Høyrokampen, alt. 1400-1440 m, Dryas assoc., 29.VIII.1957 Eckblad, p.p. (type; O). 
Table 1. The most important characters differentiating Helvella acetabulum, $H$. arctoalpina and H. dryadophila. For explanations, see 'Materials and methods' and 'Statistical analysis ...'.

\section{Character}

Apothecium size (height $\times$ diameter)

Apothecium height in relation to diameter

Stipe

Ribs of apothecium

Nature of external surface towards cup margin

Colour of hymenium

Colour of external surface in upper part of cup

Colour of external surface in lower half of dry apothecium, towards base

Spore size: ranges of length and width

Spore size: means of length and width

Shape and contents of submature spores

Length of terminal cell of paraphyses

Contents of paraphyses

Mucilaginous matter on and between paraphysis apices

Colour of hyphal wall in ental excipulum (textura intricata)

\section{H. acetabulum}

$2-8(-12) \times 2-8 \mathrm{~cm}$

usually higher than broad, at times both dimensions about equal (rather rarely distinctly broader than high)

mostly very well differentiated, prominent

\pm sharp, mostly doubleedged, branching upwards, usually reaching slightly more than half-way along cup (at times almost to the margin or less than halfway)

very delicately roughened to finely pubescent (mostly appearing glabrous to bare eye)

pale to medium brown when fresh; medium to dark brown (rarely black-brown) when dry

medium brown (rarely dark brown)

orange-tinged brown to yellow-brown, yellow towards base

(14.5-) $16.0-18.0(-21.0)$ $\times 10.0-12.5(-13.5) \mu \mathrm{m}$

$17.09 \times 11.37 \mu \mathrm{m}$

almost all ellipsoid and uniguttulate

$55-100 \mu \mathrm{m}$

subhyaline to pale brown, \pm homogeneous

scanty or lacking, very weakly cyanophilic (practically cyanophobic)

(very) slightly brownish to pale brown

\section{H. arctoalpina}

$1-2 \times 1-3(-6) \mathrm{cm}$

almost always broader than high, more pronouncedly so in age

weakly to moderately well differentiated, less prominent

\pm sharp, mostly indistinctly double-edged, branching upwards, mostly reaching about halfway along cup, at times restricted to lower part of cup

slightly more coarsely pubescent to villose

dark brown when fresh; black (rarely black-brown) most probably dark brown

dark brown, at times blackbrown (rarely medium brown)

orange-tinged brown to yellow-brown, usually with a yellowish tint at least lowest down between ribs

$(16.0-)$ 17.0-20.0(-23.5)

$\times 10.5-13.0(-15.0) \mu \mathrm{m}$

$18.06 \times 11.90 \mu \mathrm{m}$

almost all ellipsoid and uniguttulate

$25-70 \mu \mathrm{m}$

pale brown to medium brown, \pm homogeneous

fairly abundant, weakly to moderately cyanophilic

(very) slightly brownish to pale brown when fresh; black when dry

\section{H. dryadophila}

$0.5-1.5 \times 1-2 \mathrm{~cm}$

relation variable; in age mostly broader than high

weakly to moderately well differentiated, less prominent

\pm blunt, pronouncedly double, not branching, only reaching lower part of cup

finely pubescent

dark brown

dark brown to pale brown, paling downwards (without any orange or yellowish tinges)

$17.0-21.0(-25.0) \times 11.0-$ $13.5(-16.0) \mu \mathrm{m}$

$18.73 \times 12.23 \mu \mathrm{m}$

a proportion subfusiform and three-guttulate

$35-70 \mu \mathrm{m}$

medium brown to fairly dark brown, \pm granular

in moderate amount, very weakly cyanophilic (practically cyanophobic)

hyaline 
Comparison of $\mathbf{H}$. acetabulum, $\mathbf{H}$. arctoalpina and $\mathbf{H}$. dryadophila

Table 1 shows the most important characters differentiating the three species ( $H$. pocillum, which grows in habitats similar to those of the two new species and has apparently a similar type of distribution, differs from all three in its very large spores, which measure ca. $25-28 \times 13-16.5 \mu \mathrm{m}$; Harmaja 1976). Tables $2-5$ and Figs. $1-7$ and 14 and 15 may also be consulted for a comparison of different characters. Some additional notes are presented here and the results of the statistical analyses are discussed in the following section.

The apothecia of $H$. dryadophila tend to broaden gradually from the base towards the cup, especially when young (cf. Fig. 5); this tendency is not so evident in the other species.

The border between the textura intricata and $t$. angularis layers in the excipuli of $H$. acetabulum and $H$. arctoalpina is sharp, and the intercellular spaces in the latter tissue contain strongly cyanophilic matter. As a layer of $t$. prismatica is also present, composing the outermost part of the excipulum and the external 'warts', the structure of the excipulum of these two species is very similar to that of, e.g., Otidea (Harmaja 1974). Dissing (1966) did not distinguish between the $t$. angularis and $t$. prismatica layers in $H$. acetabulum coll. or in the greater part of Helvella.
Due to the more or less dark brown intracellular and encrusted pigments (discernible in Melzer's reagent as well as in $5 \% \mathrm{KOH}$ ) of the $t$. prismatica of $H$. arctoalpina (at times also in the lower part of $t$. angularis) and $H$. dryadophila, this layer is seen as the distinctly darkest part of the context in microscopic mounts, and even with the bare eye. In $H$. acetabulum, the rather pale red-brown $t$. angularis is usually the darkest part of the context, and never very pronouncedly so; occasionally, the $t$. angularis and $t$. prismatica together form the darkest part, or the excipulum is of about the same colour intensity throughout (cf. Table 1). In $H$. dryadophila, the border between the ental and ectal excipulum is very conspicuous, owing to the contrast between the $t$. intricata, with its hyaline thin-walled hyphae, and the directly adjacent $t$. prismatica, with its large inflated darkly coloured cells with thickened walls. It is probable that the darker colour in four different parts of the apothecium in the two arctic-alpine species (contents of $t$. prismatica cells, encrustation on walls of these cells, and contents and encrustation of paraphyses) is due to a single chemical compound, a single kind of pigment, at least within each of the two species. The paler $H$. acetabulum may contain the same pigment in lesser quantity or its apothecia may lack this dark compound and contain only some paler pigment.

The paraphysis contents, especially in the terminal cell, appear to display another interspecific differ-
Textura angularis

layer

\section{Textura prismatica:} colour of contents of normal cells

\begin{abstract}
T. prismatica: approximate thickness of cell wall
\end{abstract}

$T$. prismatica: colour of cell wall in normal cells

$T$. prismatica: diameter of end cell of tufts, or warts: total range and mean

Fruiting period in Fennoscandia

Zonal distribution in Fennoscandia

\section{distinct, typical, 45-85 $(-120) \mu \mathrm{m}$ thick, pale red-brown}

almost hyaline to pale brown, distinctly brown at times fulvous

distinct, typical, $(50-)$

$70-110 \mu \mathrm{m}$ thick, pale

brownish like $t$. intricata

$0.8-1.3 \mu \mathrm{m}$

$0.6-1.0 \mu \mathrm{m}$

hyaline (without coloured encrustation)

$6.0-13.0 \mu \mathrm{m} ; \bar{x}=8.54 \mu \mathrm{m}$

medium to dark brown due to encrusted layer

lacking or narrow and indistinct

distinctly brown

$0.9-2.0 \mu \mathrm{m}$

dark brown due to encrusted layer

$7.0-20.0 \mu \mathrm{m} ; \bar{x}=10.87 \mu \mathrm{m} \quad 7.5-20.0 \mu \mathrm{m} ; \vec{x}=12.02 \mu \mathrm{m}$ $\begin{array}{ll}\text { from early May to late July } & \begin{array}{l}\text { from late July to end of August } \\ \text { August }\end{array}\end{array}$

temperate to northern boreal, lower oroarctic (low very uncommon north of alpine), most probably hemiboreal zone lower and middle oroarctic (low and middle alpine), most probably also in orohemiarctic zone 


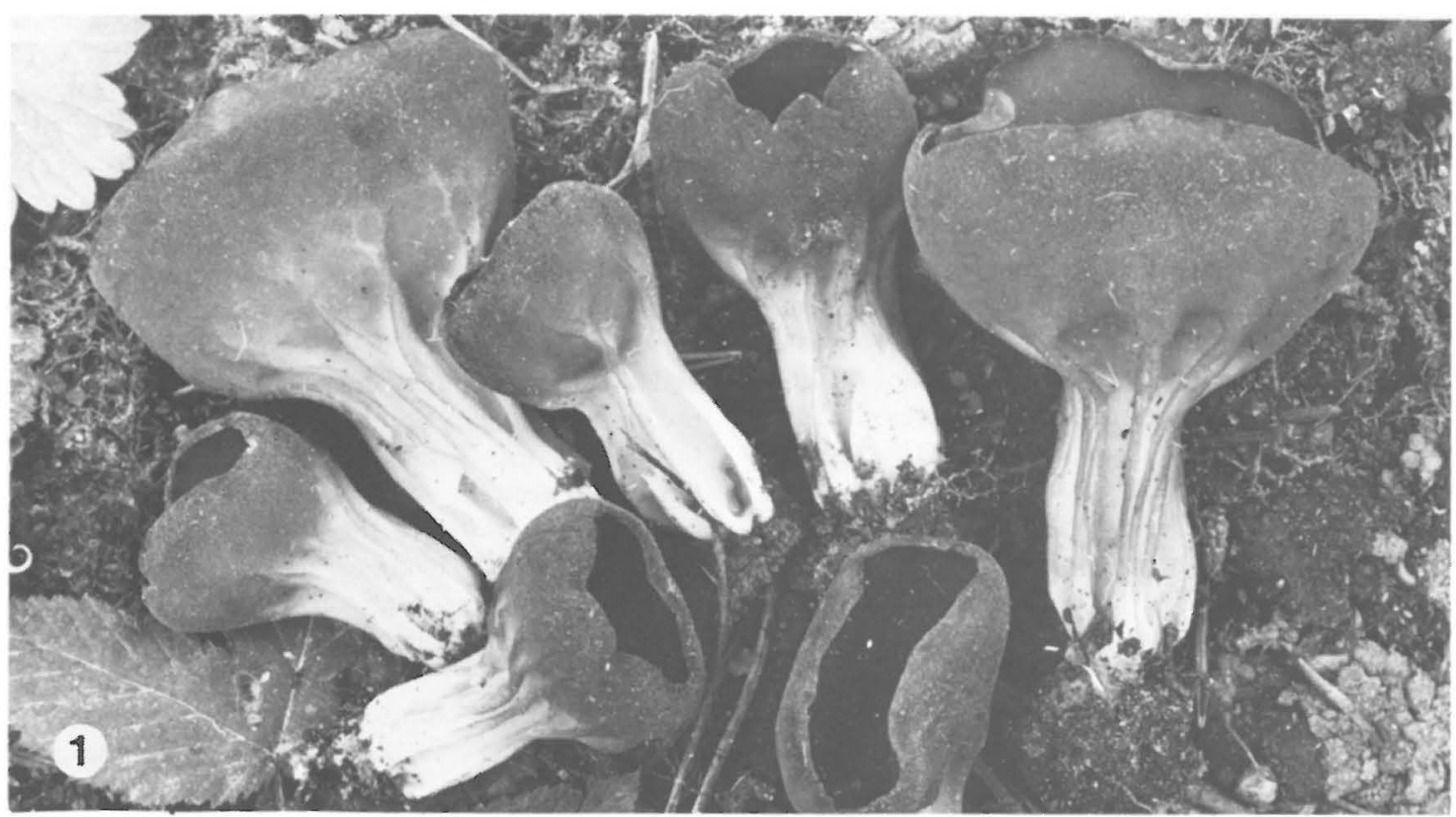

Fig. 1. Helvella acetabulum fresh in situ, in about natural size (Finland, Etelä-Savo, Lappeenranta, Ihalainen, 2.VII.1976 Korhonen, H). Photo: Mauri Korhonen. - For other photographs of typical fresh H. acetabulum, see Dissing (1966, Fig. 14a) and Weber (1972, Figs. 19-21).

ence besides that in colour intensity. In $H$. acetabulum and $H$. arctoalpina, the contents are homogeneous to very slightly granular, but in $H$. dryadophila they are rather granular. This character, though not distinct in this case, may possess significance in the group, since in $H$. pocillum the paraphysis contents are very markedly granular (Harmaja 1976).

The terminal cell of the paraphyses is pronouncedly longer in $H$. acetabulum than in the two other species. This difference would no doubt have proved highly significant if analysed statistically. The usefulness of this character in infrageneric taxonomy of the Pezizales has been almost completely ignored (but see Maas Geesteranus 1967 as concerns Peziza St-Am.).

A proportion of the submature spores of $H$. dryadophila are subfusiform and three-guttulate, but such spores are only rarely observed in the other two species (cf. Harmaja 1977). H. acetabulum is the only one of the three species in which a minor proportion of the fully mature released spores are not infrequently subfusiform.

The hyphae of the $t$. intricata are, on the average, slightly thinner in $H$. dryadophila (ca. 2.0-7.5 $\mu \mathrm{m}$ in diam.) than in $H$. arctoalpina (ca. 2.5-10.0 $\mu \mathrm{m}$ ) and $H$. acetabulum (ca. 2.0-8.0 $(-10.0) \mu \mathrm{m}$ ).
A few characters common to all three species also deserve mention. According to my studies, the ascus development is pleurorhynchous in all three (and $H$. pocillum) (cf. Weber 1972). The dried apothecia display about the same responses to ultra-violet light (UV 254): the hymenium retains its original colour with, however, faint violet and chlorine tinges; the external surface behaves in about the same way, but the originally \pm yellow or whitish colour of the base of the apothecium and the areas between the ribs becomes more pronounced. The habitats of the species appear very similar, judged from the information available: they all grow on \pm bare, distinctly calcareous, and almost always well-drained, soil. The two arctic-alpine species prefer Dryas octopetala vegetation, an interesting feature shared by surprisingly many species of macrofungi, both exclusively (oro)arctic species and those \pm wide-spread ones which reach (oro)arctic zones.

Some discussion has been devoted to the presence versus absence of a 'white margin' in the cup of the Helvella apothecium and the taxonomic significance of this character (cf. e.g. Dissing 1964 and 1966). It appears that the nature of this feature has been partly misunderstood. Dissing (1966) states that the arctic-alpine collections of $H$. acetabulum (coll.) 
Figs. 2-6. Dried apothecia of four species of the Helvella acetabulum group, $\times$ 1.5. $-2: H$. acetabulum (part of specimen no. 2 in the list of specimens examined in detail). - 3: H. arctoalpina (part of type, specimen no. 7). - 4: $H$. arctoalpina (part of specimen no. 5) - 5: $H$. dryadophila (part of type, specimen no. 2). - 6: H. pocillum (part of the apothecia separated from the mixed specimen mentioned on p. 46). - Photo: Mauri Korhonen.

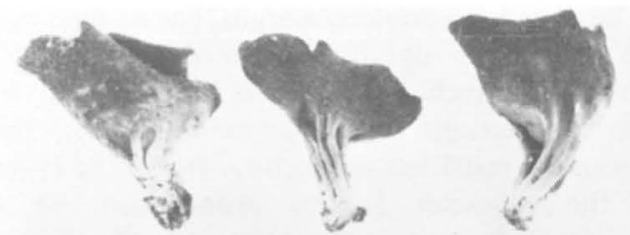

$5 \quad 2 \quad 5$
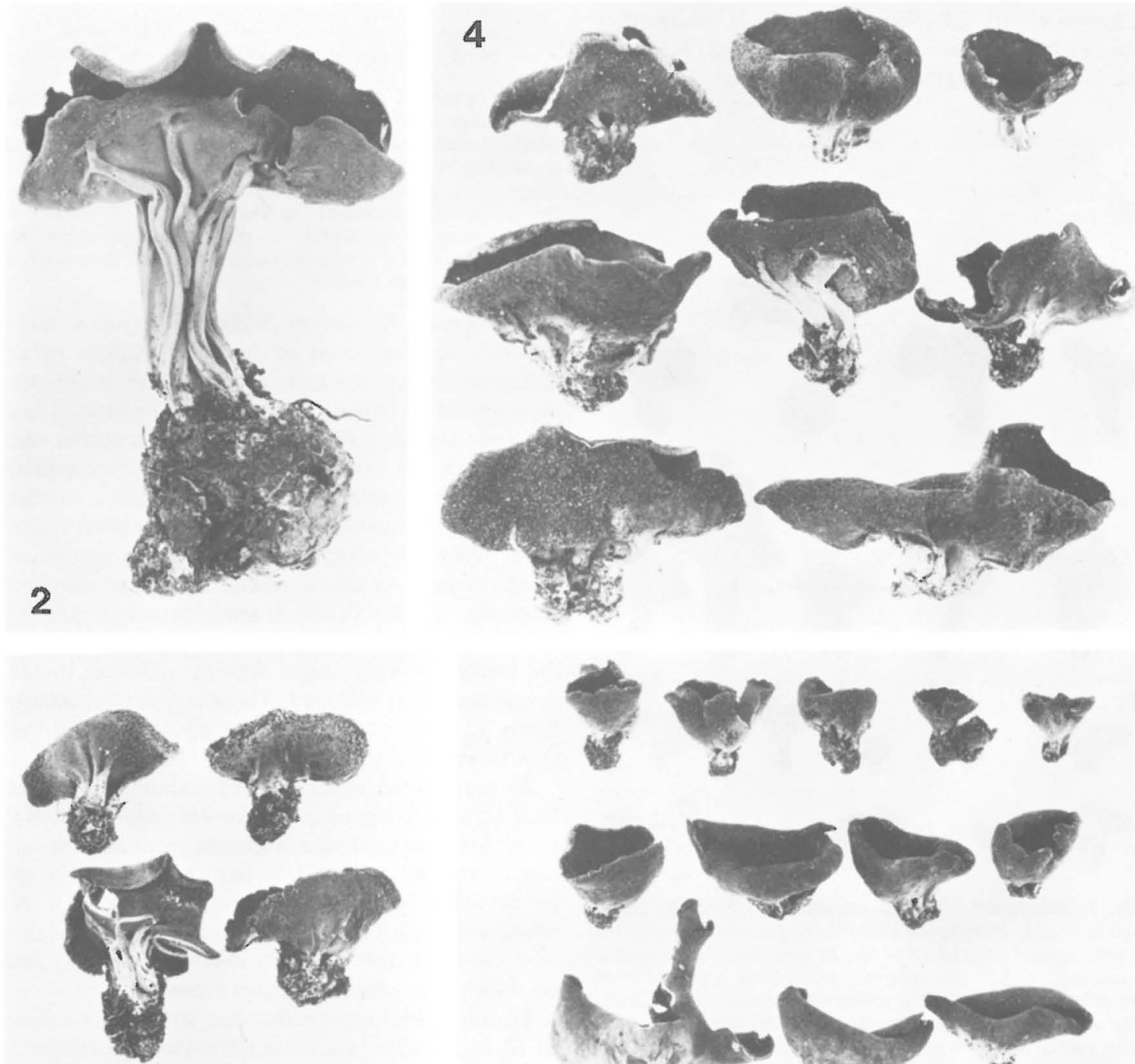

3

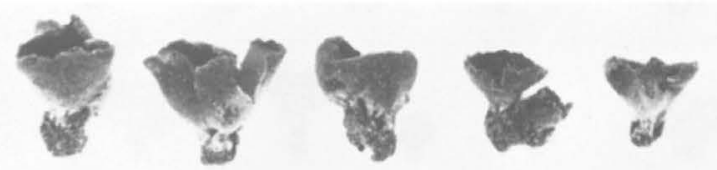

6

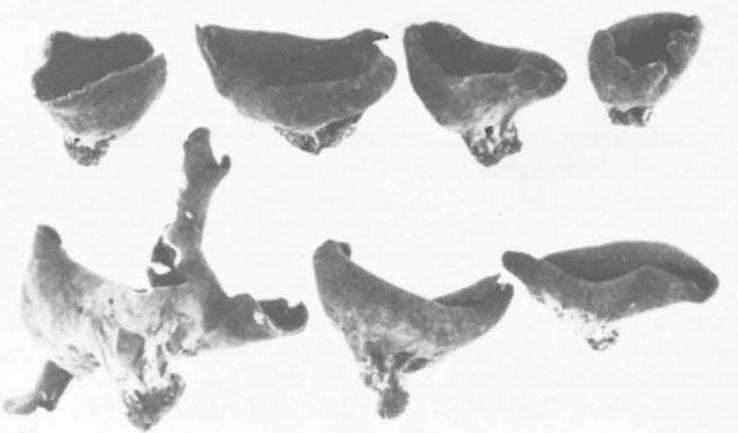


often have such a white cup margin, but he does not attach taxonomic significance to this feature. I observed that such a margin is often found in southern collections of $H$. acetabulum (i.e., the species in the restricted sense), too. But in the latter cases the character is less pronounced, so a difference of degree is present anyway. The difference is easy to reduce to a difference in the pubescence of the cup margin between $H$. acetabulum s. str. and $H$. arctoalpina (which Dissing no doubt mainly meant by the 'arctic-alpine collections'), observed in the present study. The white warts, or tufts of cell rows, are somewhat larger in the latter species, and thus more conspicuous than in $H$. acetabulum s. str. (cf. Figs. 2, 3 and 4), where they have escaped the attention of mycologists. What are these 'white marginal warts'? Dissing (1964 and
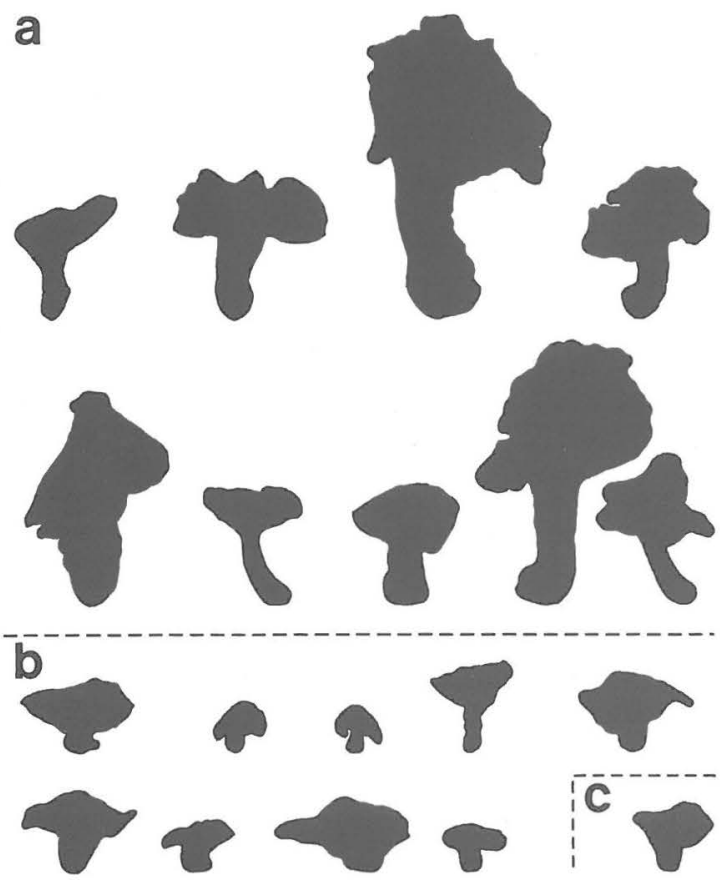

Fig. 7. Silhouettes of dried apothecia of Helvella acetabulum (a), $H$. arctoalpina (b) and $H$. dryadophila (c). One apothecium of each of 19 of the 20 specimens listed here is presented, $\times 0.5$. The specimen numbering proceeds from the upper left corner to the lower right corner in the figure. The silhouette for specimen no. 6 of $H$. arctoalpina has been partly reconstructed, having been spoilt in pressing. Specimen no. 1 of $H$. dryadophila contained such badly fragmented apothecia that it had to be excluded. Note the large apothecium, fairly high in relation to breadth, of $H$. acetabulum.

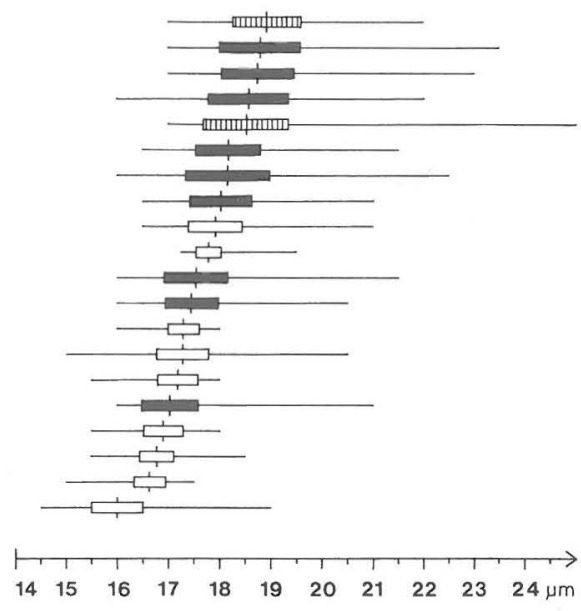

Fig. 8. Variability of spore length in specimens of Helvella acetabulum (graphs with open quadrangles), $H$. arctoalpina (solid quadrangles) and $H$. dryadophila (hatched quadrangles). The horizontal lines in the graphs show the range of variation of spore length. The quadrangle shows the confidence interval of the mean at the $95 \%$ level. The vertical bars in the middle of the quadrangle show the arithmetical mean. The ranges and means are presented in numerical form in Table 2.

1966) finds (in $H$. corium (Weberb.) Massee s. lato) that they are composed of deviating hyaline, often collapsed, cells in the tufts (warts, hairs), which are most abundant in the apical parts of the tufts. I can confirm Dissing's observations as concerns $H$. acetabulum, $H$. arctoalpina and $H$. dryadophila, and can supplement this explanation with a further observation. I have noted that these marginal hairs, in particular, are often covered with abundant small white crystals. As all the species concerned grow on substrates rich in calcium, it seems probable that the crystals are lime $\left(\mathrm{CaCO}_{3}\right)$, which is precipitated on the cell walls when water flowing upwards in the apothecium is evaporated. These crystals apparently partly account for the white margin of the cup, but to what extent is uncertain.

$H$. acetabulum occurs in Fennoscandia from sea level up to altitudes of ca. $700 \mathrm{~m}$ (Härjedalen, central Sweden). $H$. arctoalpina is known from altitudes of a few hundred metres (Finnmark, northern Norway) to ca. $1400 \mathrm{~m}$ (Oppland, southern Norway). $H$. dryadophila has so far been collected only at heights of $1200 \mathrm{~m}$ (Torne Lapland, northern Sweden) and ca. $1400 \mathrm{~m}$ (Oppland, southern Norway).

Dissing (1966) reports that the 'arctic-alpine form of $H$. acetabulum' occurs in Greenland, Switzerland, Iceland, Spitzbergen and the Scandinavian mountain range in Sweden and Norway. Without seeing all the specimens I cannot tell to which species these 

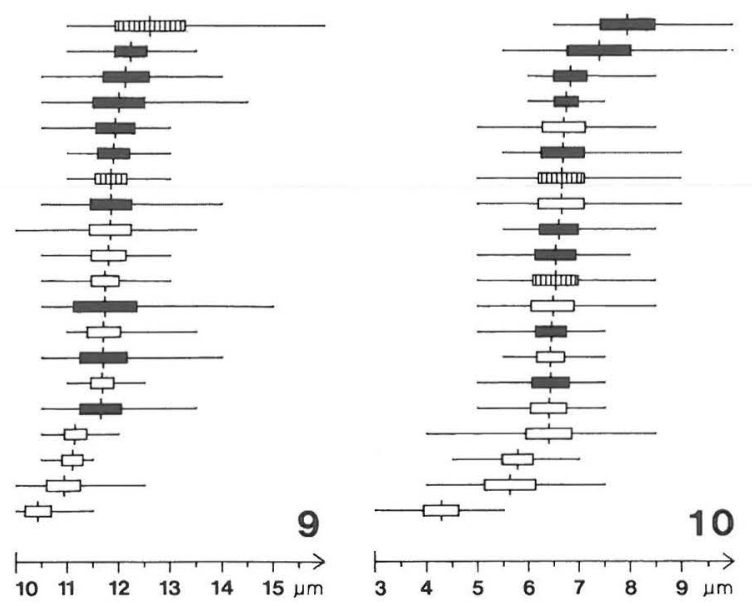

Figs. 9-10. Helvella acetabulum, $H$. arctoalpina and $H$. dryadophila. - 9: Variability of spore width. - 10: Variability of diameter of paraphysis apices. See also Tables 3 and 4 , and legend of Fig. 8.

records actually refer, and so the total distribution of $H$. arctoalpina and $H$. dryadophila (and $H$. pocillum) cannot yet be presented. However, some such specimens from beyond Fennoscandia have been seen and examined by me in addition to the great majority of the Fennoscandian specimens considered in detail in the present study (see also Addendum). The specimen from Iceland (M. Lange 659 , C) turned out to be $H$. costifera coll., while both the Greenlandic specimens (M. Lange 193 and 292, C) unexpectedly proved to be typical $H$. acetabulum s. str. It is not known in which vegetation zone the specimens from Greenland have been collected, but in any case these two specimens represent the northern/upper limit of the distribution and the latest fruiting records (August 2 and 15) of $H$. acetabulum s. str. so far known. The four species may not be completely allopatric as might have been expected.

Despite the superficial similarities between $H$. arctoalpina and $H$. dryadophila (small dark apothecia, kind of $t$. prismatica, late fruiting, arctic occurence) I consider the former species taxonomically a very close relative to $H$. acetabulum. The close relationship is shown in particular by the presence of the rather bright orange-brown to yellow-brown colour (usually with a yellow tint lowest down) in the apothecia, especially in the dried condition, and also by the kind of external ribs and the construction of the excipulum. H. dryadophila does not appear to be very close to either $H$. arctoalpina or $H$. acetabulum, being nearer to $H$. pocillum.

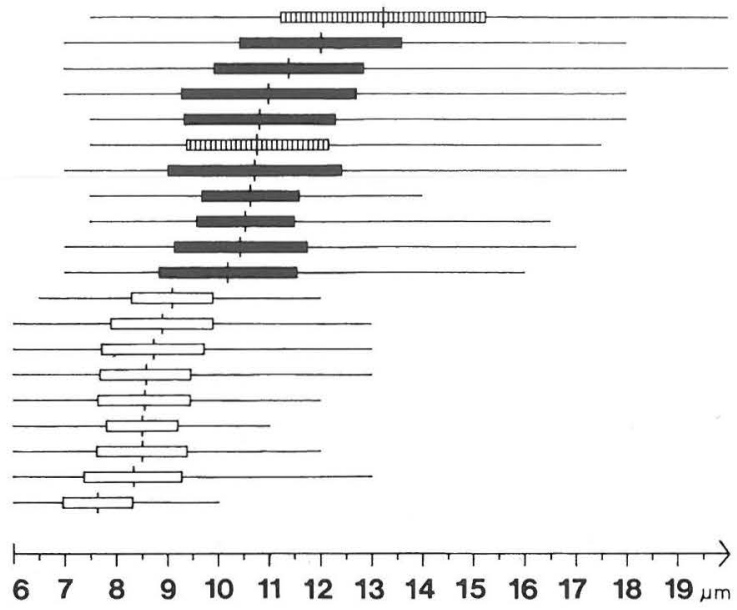

Fig. 11. Variability of diameter of excipular end cells in Helvella acetabulum, $H$. arctoalpina and $H$. dryadophila. See also Table 5 and legend of Fig. 8. - The confidence intervals and, in particular, mean values, of the specimens have obviously a higher discriminative power than the total distributions, or ranges, of the measures.

a

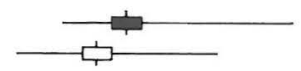

b

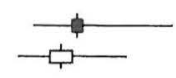

C

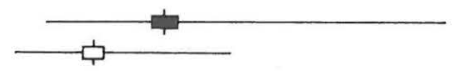

d

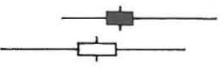

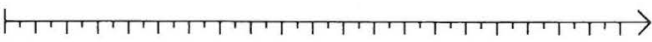

$34567891011121314151617181920212223 \mu \mathrm{m}$

Fig. 12. Specific variability of the four quantitative characters in Helvella acetabulum and $H$. arctoalpina: a) spore length, b) spore width, c) diameter of excipular end cells, d) diameter of paraphysis apices. See also Tables $2-5$ and legend of Fig. 8.

For the time being, all the three new species discovered in the neighbourhood of $H$. acetabulum, i.e. $H$. arctoalpina, $H$. dryadophila and $H$. pocillum, are best included in the section Acetabulum Diss.

In summary, as a result of the present study, $H$. acetabulum will, generally speaking, be restricted to comprise a large, rather pale, early and predominantly southern species, while $H$. arctoalpina, $H$. dryadophila (and $H$. pocillum) are small, dark, late, arctic-alpine species. 


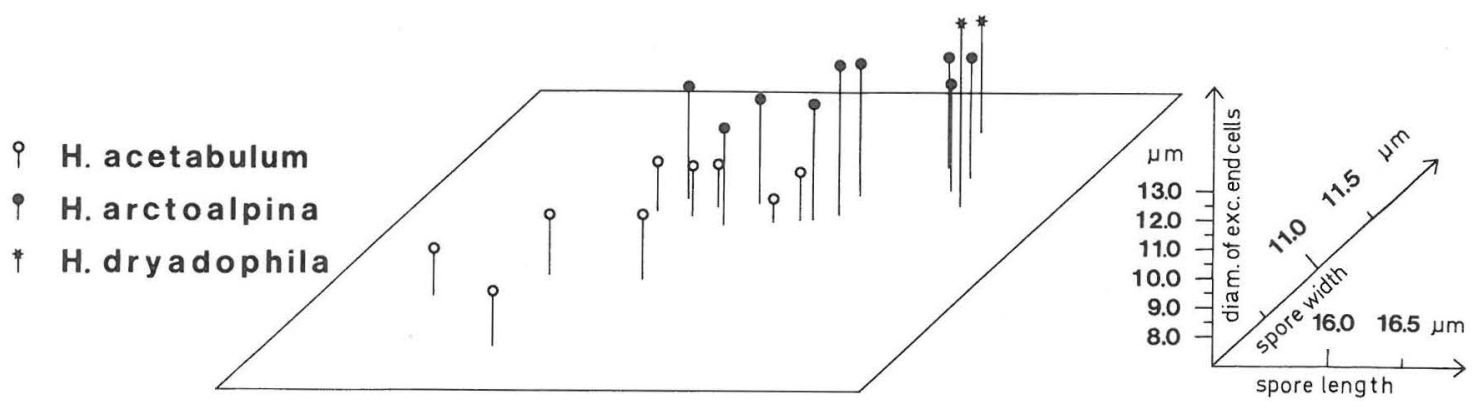

Fig. 13. Three-dimensional scatter diagram showing the variability of three quantitative characters in the 20 specimens of the three Helvella species. - Note the clustering of the short open-headed 'pins' towards bottom left, of the long solidheaded ones towards right and top, and of the long star-headed ones towards top right.

\section{Statistical analysis of four quantitative characters of $\mathbf{H}$. acetabulum, $\mathbf{H}$. arcto- alpina and H. dryadophilla}

The results of the statistical analyses of the spore length, the spore width, the diameter of the paraphysis apices, and the diameter of the excipular end cells are shown numerically in Tables $2-5$ and graphically in Figs. $8-13$. The figures $8-12$ also show the confidence intervals of the means at the 95 $\%$ level.

The confidence limits of a mean value can be considered analogous to the error of measurement of a single character. Raitviir (1972) considered the range of variation of spore measures within a single apothecium, and calculated the number of measurements of spore length and width required to give a confidence interval for the mean of the same order as the error of measurements made with an ocular micrometer at a magnification of $\times 700$. He found that in the majority of the Discomycetes (incl. $\mathrm{Hel}$ vella) the required number was $20-30$ for spore length and $\leqslant 10$ for spore width. I made 20 measurements not only of spore length but also of the three smaller dimensions, partly because I used a magnification lower than Raitviir, partly because the diameters of paraphysis apices and excipular end cells generally have a wide range of variation in a single apothecium.

The present comparison of the measures of the four characters in $H$. acetabulum and $H$. arctoalpina could also have been performed with statistical tests other than the $t$ test. Some type of variance analysis is also no doubt useful in treatments of material of this kind, even when a character is compared between only two species; if more than two species are compared, Student's t test cannot be used and the analysis of variance is apparently the most suitable of the various tests.
In comparisons of this kind, the objects measured must naturally be homologous entities at the same stage of development. Some difficulties are encountered in the measurement of spore lengths and widths in Helvella. In sections in the usual Melzer mounts, the measures of submature spores have unexpectedly proved to be greater than those of fully mature ones released from the asci. To ensure that only mature spores are obtained, care must be taken not to squash the section; pressure on the cover glass releases many submature and even quite young spores. Besides their frec occurrence on the hymenial (and often also excipular) surface, the mature spores can also be recognized by their hyaline appearance; the contents of the submature ones, excluding the oil drop(s), appear slightly coloured, faintly yellowish. The difference is not conspicuous, but with some experience most spores can be classified as fully mature or not. I have noted (unpublished) the same phenomenon in the genus Otidea, where the mature spores of almost every species are easily distinguished from those at younger stages of

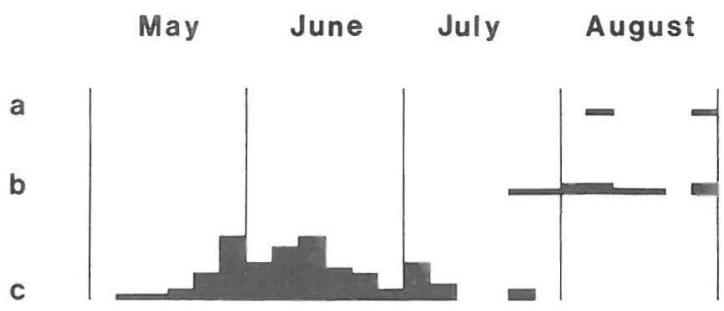

Fig. 14. Phenological diagram showing the fruiting periods of Helvella acetabulum (c), $H$. arctoalpina (b) and $H$. dryadophila (a) in Fennoscandia. The diagram is based on the dates, when exact, on the labels of all the Fennoscandian specimens actually seen by the author, except for three records of $H$. acetabulum (see legend of Fig. 15). Each month is divided into six periods of five days. The shading of the columns shows the number of specimens collected in a period. 


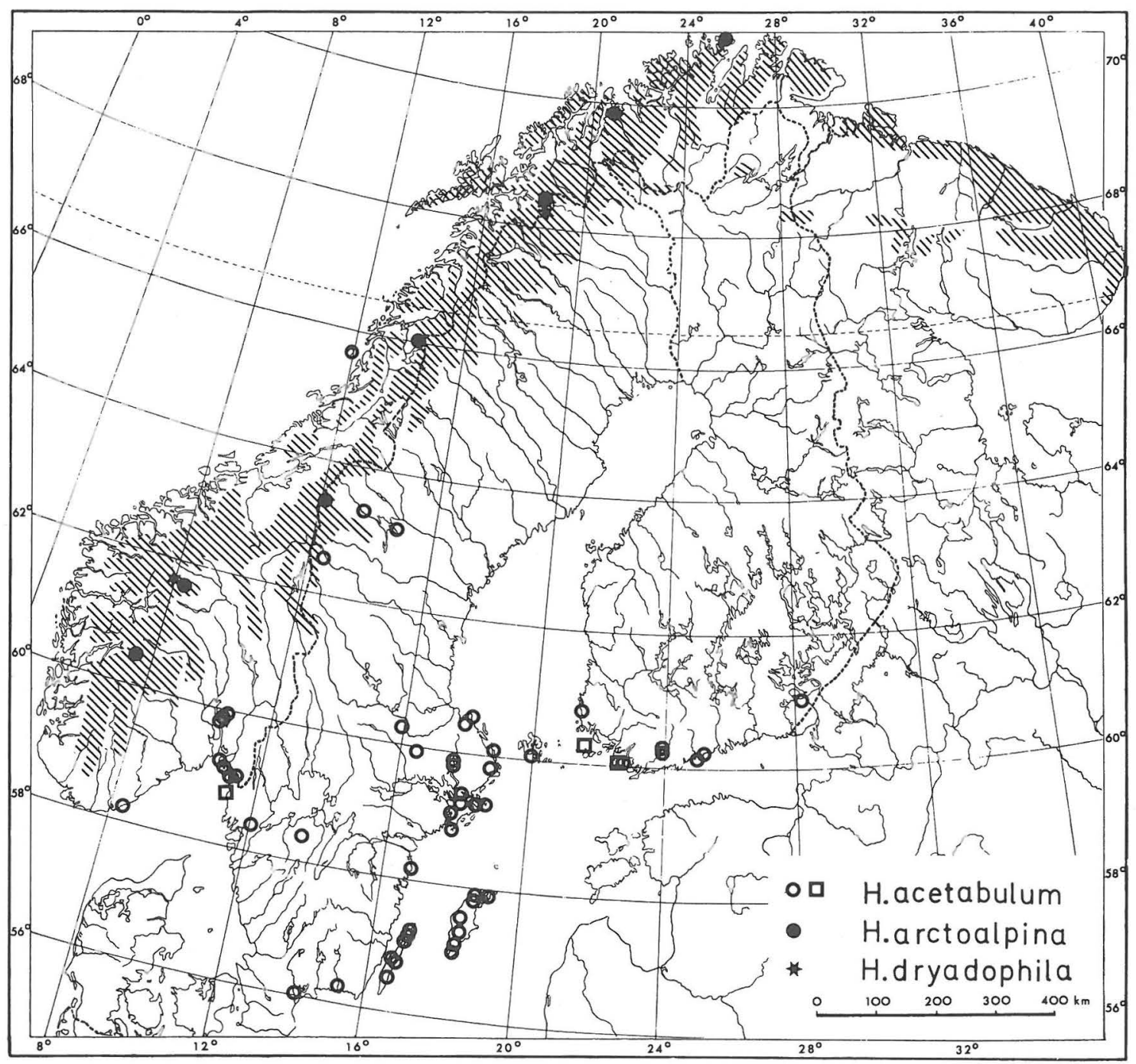

Fig. 15. Map of distributions of the three Helvella species in Fennoscandia. Based on all the specimens actually seen by the author, except for three records from the literature: the open squares represent obvious H. acetabulum s. str. (Mäkinen 1963; Jacobsson 1976). The oroarctic (alpine) area, according to Ahti et al. (1968), has been hatched. - Stars also show the two known localities of $H$. pocillum.

development by the conspicuous de Bary gas bubble they each contain. This phenomenon, that submature spores are larger than released fully mature ones, may be fairly common in the Pezizales and should be carefully considered in taxonomic work.

Another thing to be noted concerning the spores of Helvella has already been pointed out by Dissing \& Nannfeldt (1966); in many of the species, occasional spores are often unusually large, even at the fully mature stage ('macrospores'). The asci bearing them are nevertheless eight-spored, but some or all of the remaining spores are probably slightly smaller than usual.

These two phenomena contribute to widen the ranges of the spore dimensions, especially length, reported in the literature for single specimens and species of Helvella. When only fully mature spores are considered and the influence of the macrospores is kept under control, the ranges and mean values of the spore measurements can be somewhat diminished, and more quantitative differences between species will no doubt become apparent. 
Table 2 and Fig. 8 reveal that the spores of $H$. acetabulum are shorter than those of the other two species. The difference between $H$. acetabulum and $H$. arctoalpina proved significant at the $99 \%$ level $(p<0.01)$. It is very probable that larger material would have shown this difference to be highly significant. It is also obvious that the deviation in individual specimens is greater in $H$. arctoalpina and $H$. dryadophila than in $H$. acetabulum, no doubt significantly so. This largely results from the occurrence of occasional macrospores in the two former species. I believe, however, that even if such spores were eliminated from measurements, differences in spore length would exist between the species. Moreover, the occurrence of macrospores is probably genetically controlled, and these spores could justifiably be included in comparisons concerning genetic diversity.

Table 2. Variability of spore length in $\mu \mathrm{m}$ in Helvella acetabulum, $H$. arctoalpina and $H$. dryadophila. S.D. = standard deviation of the mean, S.E. = standard error of the mean. Student's test was used in the comparison of the mean values of the specimens of $H$. acetabulum and $H$. arctoalpina, and the value of $\mathrm{t}(\mathrm{df}=16)$ is shown. For further explanations, e.g. concerning numbering of specimens, consult 'Materials and methods'.

Specimen no.
H. acetabulum
1
2
3
4
5
6
7
8
9

all specimens

$$
\text { Kange }
$$

$\begin{array}{ccc}\text { Mean } & \text { S.D. } & \text { S.E } \\ & & \\ 16.78 & 0.70 & 0.16 \\ 17.28 & 1.09 & 0.24 \\ 17.30 & 0.64 & 0.14 \\ 17.78 & 0.50 & 0.11 \\ 16.63 & 0.67 & 0.15 \\ 16.90 & 0.79 & 0.18 \\ 17.18 & 0.80 & 0.18 \\ 17.93 & 1.13 & 0.25 \\ 16.00 & 1.08 & 0.24 \\ 17.09 & 0.59 & 0.20\end{array}$

Table 3 and Fig. 9 show that spore width is likewise greater in the two arctic-alpine species; the difference between $H$. acetabulum and $H$. arctoalpina is significant at the $99 \%$ level ( $p<0.01$ ). Larger material would presumably prove this difference highly significant.

The paraphysis tips are on the average wider in $H$. arctoalpina and $H$. dryadophila than in $H$. acetabulum (Table 4 and Fig. 10). However, the difference between $H$. acetabulum and $H$. arctoalpina was only fairly significant, i.e. at the $95 \%$ level (p $<0.05$ ). In all three species the range of the measures within an apothecium is usually wide and the shape of the apex often varies (from practically filiform through clavate to subcapitate).

A marked difference was found between $H$. acetabulum and the two arctic-alpine species in the diameter of the end cells in the tufts ('warts', 'hairs') of the end cells are wider in the two arctic-alpine species (Table 5 and Fig. 11). The difference

Table 3. Variability of spore width in Helvella acetabulum, $H$. arctoalpina and $H$. dryadophila. For explanations, see legend of Table 2.

Specimen no.

Range

Mean S.D.

S.E.

$H$. acetabulum
1
2
3
4
5
6
7
8
9
all specimens$$
14.5-19.0
$$

$3.43 * *$ the $t$. primatica in the external surface of the cup:

$$
\begin{aligned}
& 10.0-11.5 \\
& 10.0-13.5 \\
& 10.5-11.5 \\
& 11.0-12.5 \\
& 10.5-12.0 \\
& 10.5-13.0 \\
& 10.5-13.0 \\
& 11.0-13.5 \\
& 10.0-12.5
\end{aligned}
$$

$\begin{array}{lll}10.43 & 0.52 & 0.12 \\ 11.83 & 0.85 & 0.19 \\ 11.10 & 0.38 & 0.09 \\ 11.68 & 0.44 & 0.10 \\ 11.15 & 0.46 & 0.10 \\ 11.80 & 0.73 & 0.16 \\ 11.73 & 0.60 & 0.13 \\ 11.70 & 0.68 & 0.15 \\ 10.93 & 0.65 & 0.15 \\ \mathbf{1 1 . 3 7} & 0.49 & 0.16\end{array}$

$3.01 * *$

\section{H. arctoalpina}

1
2
3
4
5
6
7
8
9
all specimens
H. dryadophila
1
2
all specimens

0.21

0.21

0.19

0.19

0.17

0.24

0.29

0.14

0.14 0.07 $\begin{array}{ll}11.70 & 0.94\end{array}$

$\begin{array}{ll}12.13 & 0.94\end{array}$

$\begin{array}{ll}11.65 & 0.83\end{array}$

$11.85 \quad 0.86$

$\begin{array}{ll}11.93 & 0.77\end{array}$

$12.00 \quad 1.08$

$\begin{array}{ll}11.73 & 1.29\end{array}$

$12.23 \quad 0.64$

$11.90 \quad 0.64$

$11.90 \quad 0.20$

$10.5-15.0$

$11.0-13.0$

$11.0-16.0$

$11.0-16.0$ $\begin{array}{ll}11.85 & 0.67\end{array}$

$12.60 \quad 1.42$

$\begin{array}{ll}12.23 & 0.53\end{array}$

\section{H. dryadophila \\ all specimens}

$\begin{array}{llll}17.0-22.0 & 18.93 & 1.41 & 0.31 \\ 17.0-25.0 & 18.53 & 1.74 & 0.39 \\ 17.0-25.0 & \mathbf{1 8 . 7 3} & 0.28 & 0.20\end{array}$

all specimens 
between $H$. acetabulum and $H$. arctoalpina was highly significant, at the $99.9 \%$ level (i.e., $\quad$ p < 0.001).

These terminal cells varied widely within a single apothecium in all three species, but the infraspecific variation was not great in the two with sufficient material (see Table 5). The variation within apothecium partly depends on the size of the tufts: in larger distinct tufts, the cells, including the terminal ones, are smaller than in lower indistinct tufts. The standard deviation is of about the same magnitude within $H$. acetabulum and $H$. arctoalpina, so the distributions of the measurements and means of this character can well be compared and tested statistically. The other cells of the $t$. prismatica are also wider in $H$. arctoalpina and $H$. dryadophila, and the difference in diameter is most probably even greater if the inner cells of the $t$. prismatica are compared.

The microscopic characters differentiating $H$. acetabulum most clearly from $H$. arctoalpina and $H$. dryadophila are those of the $t$. prismatica, and the less conspicuous feature of the length of the paraphysis end cells. In the two new species the cells of the $t$. prismatica are large and have dark brown encrusted pigment and the terminal cells of the paraphyses are short, while in $H$. acetabulum the firstnamed cells are smaller, especially narrower, and lack brown wall encrustation (it occurs very rarely in some cells, and is then restricted to areas near the septa) and the paraphysis end cells are longer.

The three-dimensional scatter diagram in Fig. 13 shows as combined the variation of the mean values for spore length, spore width and the diameter of the excipular end cells among the 20 specimens of the three species. A very distinct positive correlation exists between the measures of these three characters, especially when the species are compared.

The variation in the four quantitative characters of the species does not show any clinal tendency when the values for specimens from different localities are compared. The four characters even vary widely between specimens from the same fjelds or the same areas.
Table 4. Variability of diameter of paraphysis apices in Helvella acetabulum, $H$. arcioalpina and $H$. dryadophila. For explanations, see legend of Table 2.

$\begin{array}{lcccc}\text { Specimen no. } & \text { Range } & \text { Mean } & \text { S.D. } & \text { S.E. } \\ \text { H. acetabulum } & & & & \\ 1 & & & & \\ 2 & 4.0-8.5 & 6.40 & 0.98 & 0.22 \\ 3 & 3.0-5.5 & 4.28 & 0.70 & 0.16 \\ 4 & 5.0-8.5 & 6.48 & 0.88 & 0.20 \\ 5 & 5.0-8.5 & 6.70 & 0.91 & 0.20 \\ 6 & 4.5-7.0 & 5.78 & 0.64 & 0.14 \\ 7 & 5.0-9.0 & 6.65 & 0.99 & 0.22 \\ 8 & 4.0-7.5 & 5.63 & 1.06 & 0.24 \\ 9 & 5.0-7.5 & 6.40 & 0.75 & 0.17 \\ \text { all specimens } & 5.5-7.5 & 6.43 & 0.57 & 0.13 \\ & 3.0-9.0 & 6.08 & 0.77 & 0.26\end{array}$

2.49

$\begin{array}{lllll}\text { H. arctoalpina } & & & & \\ 1 & 6.5-10.0 & 7.95 & 1.10 & 0.25 \\ 2 & 5.0-7.5 & 6.45 & 0.69 & 0.15 \\ 3 & 5.5-10.0 & 7.40 & 1.34 & 0.30 \\ 4 & 5.5-9.0 & 6.68 & 0.91 & 0.20 \\ 5 & 5.5-8.5 & 6.60 & 0.80 & 0.18 \\ 6 & 6.0-8.5 & 6.83 & 0.69 & 0.16 \\ 7 & 6.0-7.5 & 6.75 & 0.50 & 0.11 \\ 8 & 5.0-7.5 & 6.43 & 0.75 & 0.17 \\ 9 & 5.0-8.0 & 6.53 & 0.87 & 0.19 \\ \text { all specimens } & 5.0-10.0 & 6.85 & 0.51 & 0.17 \\ & & & & \\ \text { H. dryadophila } & & & & \\ 1 & 5.0-8.5 & 6.53 & 0.92 & 0.21 \\ 2 & 5.0-9.0 & 6.65 & 0.99 & 0.22 \\ \text { all specimens } & 5.0-9.0 & 6.59 & 0.08 & 0.06\end{array}$

Table 5. Variability of diameter of excipular end cells in Helvella acetabulum, $H$. arctoalpina and $H$. dryadophila. For explanations, see legend of Table 2.

$\begin{array}{lcccc}\text { Specimen no. } & \text { Range } & \text { Mean } & \text { S.D. } & \text { S.E. } \\ \text { H. acetabulum } & & & & \\ 1 & & & & \\ 2 & 6.0-13.0 & 8.73 & 2.14 & 0.48 \\ 3 & 6.0-13.0 & 8.33 & 2.00 & 0.45 \\ 4 & 6.5-12.0 & 9.10 & 1.71 & 0.38 \\ 5 & 6.0-10.0 & 7.63 & 1.44 & 0.32 \\ 6 & 6.0-13.0 & 8.90 & 2.13 & 0.48 \\ 7 & 6.0-12.0 & 8.55 & 1.93 & 0.43 \\ 8 & 6.0-13.0 & 8.58 & 1.87 & 0.42 \\ 9 & 6.0-11.0 & 8.50 & 1.42 & 0.33 \\ \text { all specimens } & 6.0-12.0 & 8.50 & 1.86 & 0.42 \\ & 6.0-13.0 & 8.54 & 0.41 & 0.14\end{array}$

$10.17^{* * * *}$

$\begin{array}{lllll}\text { H. arctoalpina } & & & & \\ 1 & 7.5-18.0 & 10.83 & 3.19 & 0.71 \\ 2 & 7.0-18.0 & 11.00 & 3.61 & 0.81 \\ 3 & 7.0-16.0 & 10.20 & 2.91 & 0.65 \\ 4 & 7.0-17.0 & 10.45 & 2.76 & 0.62 \\ 5 & 7.0-20.0 & 11.40 & 3.09 & 0.69 \\ 6 & 7.5-16.5 & 10.55 & 2.02 & 0.45 \\ 7 & 7.0-18.0 & 12.03 & 3.35 & 0.75 \\ 8 & 7.5-14.0 & 10.65 & 2.01 & 0.45 \\ 9 & 7.0-18.0 & 10.73 & 3.61 & 0.81 \\ \text { all specimens } & 7.0-20.0 & 10.87 & 0.55 & 0.18 \\ & & & & \\ \text { H. dryadophila } & & & & \\ 1 & 7.5-20.0 & 13.25 & 4.27 & 0.96 \\ 2 & 7.5-17.5 & 10.78 & 2.97 & 0.66 \\ \text { all specimens } & 7.5-20.0 & \mathbf{1 2 . 0 2} & 1.75 & 1.23\end{array}$




\section{Latin descriptions of $\mathbf{H}$. arctoalpina and H. dryadophila}

Helvella arctoalpina Harmaja n. sp. - Helvellae acetabuli similis. Ab ea differt praecipue statura minore, stipite breviore et coloribus obscurioribus apothecii, cellulis distalibus texturae prismaticae crassioribus brunneoincrustatis, fructificatione seriore et distributione arctoalpina. - Typus: Norway, prov. Hordaland, par. Eidfjord, fjeld Dyranut, Dryas octopetola heath, 1.VIII.1959 F.-E. Eckblad (O).

Helvella dryadophila Harmaja n. sp. - Helvellae arctoalpinae valde similis sed ab ea plurimum differt: costae apothecii obtusae; apothecia sicca sine coloribus aurantiobrunneis, flavobrunneis vel flavis; hyphae texturae intricatae excipuli hyalinotunicatae; excipulum sine textura angulari. - Typus: Norway, prov. Oppland, par. Lom, fjeld Høyrokampen, alt. 1400-1440 m, Dryas octopetala assoc., 29.VIII.1957 F.-E. Eckblad, p.p. (O).

Acknowledgements. My thanks are due to Ann-Elise Torkelsen, Lic. Phil. (O), Prof. Rolf Santesson (S), Dr. Roland Moberg (UPS), Prof. Rolf Dahlgren (C), Dr. Reino Alava (TUR) and Dr. Lalli Laine (HFR) for arranging the loans of $H$. acetabulum coll. from their herbaria. Pekka Pakarinen, Lic. Phil., gave help with the calculator and Mr. Mauri Korhonen took the excellent photographs. I am grateful for financial support from the Academy of Finland and the foundation 'Jenny ja Antti Wihurin rahasto'.

\section{Addendum}

I am obliged to Mr. Ola Skifte, Troms $\emptyset$ Museum, Norway, for the loan the specimens of $H$. acetabulum coll. from that herbarium (TROM), too. However, they reached me so late that the 3 specimens of $H$. arctoalpina and one of $H$. dryadophila, detected by me among the borrowed specimens, are only listed below in this addendum. They were not examined statistically, but otherwise their information could be considered in the study and be incorporated in Table 1 and Figs. 14 and 15 (but not in Fig. 7).

Both the specimens from Spitzbergen originate from the middle arctic zone, which is present at and near the sea level there (Eurola 1968).

\section{H. arctoalpina}

Norway. Nordland: Hemnes, W of Okstindan, between Bjuråga and Jordåga, in Dryas octopetala heath on limestone, 17.VIII.1968 Sivertsen; Troms: Skjervøy, Langneset, Gjøvarden, on limestone above forest limit, 6.VIII.1963 Skifte 2580 \& Trefall. - Spitzbergen. West Spitzbergen: Woodfjorden, bottom of Bockfjorden, on mossy ground, 7.VIII.1960 Skifte 949 .

\section{H. dryadophila}

Spitzbergen. West Spitzbergen: Woodfjorden, bottom of Bockfjorden, in somewhat moist Dryas octopetala vegetation, 7.VIII.1960 Skifte 967.

\section{References}

Ahti, T., Hämet-Ahti, L. \& Jalas, J. 1968: Vegetation zones and their sections in northwestern Europe. Ann. Bot. Fennici 5: 169-211.

Dissing, H. 1964: Studies in arctic and subarctic Discomycetes 1. The genus Helvella. - Bot. Tidsskr. 60: $108-128$.

- n-1966: The genus Helvella in Europe with special emphasis on the species found in Norden. - Dansk Bot. Ark. 25: $1-172$.

Dissing, H. \& Nannfeldt, J.A. 1966: Helvella cupuliformis sp. nov., H. villosa (Hedw. ex O. Kuntze) comb. nov., H. macropus (Pers. ex Fr.) Karst., and their allies. Svensk Bot. Tidskr. 60: $325-337+$ pls. $1-3$.

Eurola, S. 1968: Über die Fjeldheidevegetation in den Gebieten von Isfjorden und Hornsund in Westspitzbergen. - Aquilo, Ser. Bot. 7: 1-56.

Harmaja, H. 1974: The generic limit between Otidea and Tarzetta (Pustularia auct.). - Karstenia 14: 138-142.

- "-1976: New species and combinations in the genera Gyromitra, Helvella and Otidea. - Karstenia 15: 2932 .
Harmaja, H. 1977: A note on Helvella solitaria (syn. H. queletii) and H. confusa n. sp. - Karstenia 17: 4044.

Jacobsson, S. 1976: Svampåren 1974-1975 i sydvästra Sverige. - Götebors Svampklubb Årsskrift 19751976: 63-67.

Kallio, P. \& Kankainen, E. 1964: Notes on the macromycetes of Finnish Lapland and adjacent Finnmark. - Ann. Univ. Turku (A 2) 32 (Rep. Kevo Subarct. Sta. 1): $178-235$.

Maas Geesteranus, R.A. 1967: De fungi van Nederland 2a. Pezizales 1 (Discinaceae, Helvellaceae, Morchellaceae, Pezizaceae, Rhizinaceae). - Wetensch. Mededel. Koninkl. Nederlandse Natuurh. Veren. 69: 1-72.

Mäkinen, Y. 1963: Mutinus caninus Huds. and Peziza acetabulum L. in Finland. - Karstenia 6-7: 108110.

Raitviir, A. 1972: Statistical methods and species delimitation in the genus Otidea. - Persoonia 6: 415-423.

Weber, N.S. 1972: The genus Helvella in Michigan. Michigan Bot. 11: 147-201.

Accepted for publication

on February 9, 1977

(addendum April 26, 1977) 